\title{
Package Reliability Verification of Vanadium Oxide Thin-film Element
}

\author{
Beom-Su Kim, ${ }^{1}$ Bong-Jun Kim, ${ }^{2}$ Sungkwan-Youm, ${ }^{3 *}$ and Dae-Hee Park ${ }^{3 * *}$ \\ ${ }^{1}$ SongBaek E\&S, Yakchon-ro 8-gil 20-23, Iksan-si Jeollabuk-do 54630, South Korea \\ ${ }^{2}$ Switching Plus, ETRI Convergence Technology Commercialization Center, \\ Gajeong-ro 218, Yuseong-gu, Daejeon 34129, South Korea \\ ${ }^{3}$ Department of Information \& Communication Engineering, Wonkwang University, \\ Iksandae-ro 460, Iksan, Jeonbuk 54538, South Korea
}

(Received June 30, 2019; accepted January 19, 2020)

Keywords: vanadium oxide, $\mathrm{VO}_{2} / \mathrm{AIN} / \mathrm{Si}$, MIT, sensor, resistance, reliability

Vanadium oxide $\left(\mathrm{VO}_{2}\right)$ is a typical metal-insulator transition (MIT) material currently receiving considerable attention because of its MIT occurring at the transition temperature $T_{C}$ of $67{ }^{\circ} \mathrm{C}$. In this study, $\mathrm{VO}_{2} / \mathrm{AlN} / \mathrm{Si}$ MIT devices with specific temperature sensor characteristics were designed and packaged for commercial use, and their temperature resistance and humidity dependences were studied to determine whether the characteristics of the elements changed over time. Clear epoxy was used as a packaging material. Reliability tests were conducted by fabricating two oxide device package types: SMD 1608 and a $3 \Phi$ lamp package used for light-emitting diodes. In high-temperature $\left(60{ }^{\circ} \mathrm{C}\right)$ storage, low-temperature $\left(-25^{\circ} \mathrm{C}\right)$ storage, and high-temperature $\left(60{ }^{\circ} \mathrm{C}\right)$ operation tests, the resistance change was $10 \%$ compared with the initial resistance. However, in the high-temperature/high-humidity test $\left(85{ }^{\circ} \mathrm{C} / 85 \% \mathrm{RH}\right)$, the resistance increased by $20 \%$, and the resistance also decreased on the order of $10^{3}$. Furthermore, when epoxy was applied to each package after conducting a high-temperature/ high-humidity test, the resistance increased by $22 \%$.

\section{Introduction}

Vanadium oxide $\left(\mathrm{VO}_{2}\right)$ is a typical metal-insulator transition (MIT) material. ${ }^{(1-3)}$ MIT structures contain a very complex and diverse range of oxides including $\mathrm{VO}, \mathrm{V}_{2} \mathrm{O}_{3}, \mathrm{VO}_{2}$, and $\mathrm{V}_{2} \mathrm{O}_{5}$, whose stability depends on the oxygen content, with the Magneli phase existing between $\mathrm{V}_{2} \mathrm{O}_{3}$ and $\mathrm{VO}_{2}$. A typical characteristic of vanadium is its MIT at around a specific temperature $\left(68{ }^{\circ} \mathrm{C}\right)$ because it has a tetragonal rutile structure above its transition temperature. There is also a transition to a $\mathrm{V}-\mathrm{O}-\mathrm{V}$ junction, that is, a metal bond, accompanied by a change in monoclinic crystal structure in the covalent bond below the transition temperature. ${ }^{(4-7)}$ This change in crystal structure is being actively developed for use in superfast switching devices owing to its switching time of $1-10$ fs.

MIT is induced by various external factors such as light, heat, electricity, pressure, and magnetic field, and its usage in sensor is increasing. It is being studied for applications in

\footnotetext{
*Corresponding author: e-mail: skyoum@gmail.com

** Corresponding author: e-mail: parkdh@wku.ac.kr

https://doi.org/10.18494/SAM.2020.2530
} 
devices such as temperature sensors, optical filters, and actuators. However, there is little research on MIT applications in commercial packaging compared with that on MIT applications in device fabrication. The development of MIT-based applications will progress further when various packaging materials are developed to suit the characteristics of oxides and the usage environment of various sensors.

In this study, MIT materials with sensor characteristics for a specific temperature were designed and packaged for commercial use, and their resistance temperature and humidity dependences were studied to determine whether the characteristics of the materials changed over time. The MIT materials comprise a $\mathrm{VO}_{2}$ thin film with a thickness of $200 \mathrm{~nm}$ deposited on a silicon substrate with an aluminum nitride (AIN) layer thickness of more than $500 \mathrm{~nm}$. The thin film with the $\mathrm{VO}_{2} / \mathrm{AIN} / \mathrm{Si}$ structure has a $T_{C}$ of about $80{ }^{\circ} \mathrm{C}$ and is manufactured as a material through a semiconductor element manufacturing process.

The designed device has an insulation resistance of about $50 \mathrm{M} \Omega$ at room temperature and a temperature resistance of less than $5 \mathrm{k} \Omega$ above $80{ }^{\circ} \mathrm{C}$. The SMD1608 package process using epoxy, a clear compound packaging material, was used in reliability tests.

The effects of temperature change on the crystallinity of $\mathrm{VO}_{2}$ and the electrical characteristics of the sensor, i.e., temperature resistance, were evaluated. The temperature resistance of $\mathrm{VO}_{2}$ in the high-temperature, low-temperature, and high-humidity operation tests is reviewed to confirm the feasibility of these MIT materials for commercialization.

\section{2. $\mathrm{VO}_{2}$ Packaging}

\section{$2.1 \mathrm{VO}_{2} / \mathrm{AIN} / \mathrm{Si}$ thin film growth}

$450 \mu \mathrm{m}$ thick N-type (100) silicon substrates were used for $\mathrm{VO}_{2} / \mathrm{AIN} / \mathrm{Si}$ thin film growth. The substrates were ultrasonically cleaned in isopropyl alcohol, acetone, and ethanol solutions for $15 \mathrm{~min}$ to remove organic materials and impurities from the surface of the substrate before washing them in distilled water. The first layer, an AIN thin film was deposited using an RF sputtering system at a base pressure of $1.5 \times 10^{-6}$ Torr. The argon and nitrogen flow rates were adjusted to target $\mathrm{Al}$ (Tasco Co.) with $99.9 \%$ purity.

AIN thin films were grown to a thickness of $500 \mathrm{~nm}$ at a deposition pressure of $7 \mathrm{mTorr}$, a deposition temperature of $350{ }^{\circ} \mathrm{C}$, and an $\mathrm{RF}$ power of $200 \mathrm{~W}$. The second layer, a $\mathrm{VO}_{2}$ film, was grown at a determined ratio (1:7) of argon to oxygen using the 99.9\%-purity vanadium (ProTech Co.) target, and the distance between the substrate and the target was maintained at $60 \mathrm{~mm}$.

A crystalline vanadium dioxide thin film was fabricated with a thickness of $200 \mathrm{~nm}$ at a growth pressure of 5 mTorr, a deposition temperature of $500{ }^{\circ} \mathrm{C}$, and an RF power of $300 \mathrm{~W}$. Presputtering was performed for about $20 \mathrm{~min}$ to generate plasma before deposition, to remove the natural oxide film and contaminants from the target surface, and to stabilize the plasma. Figure 1 shows each layer of the wafer grown by sputtering and analyzed by TEM. Figure 1(a) shows a bright TEM image of the $\mathrm{VO}_{2}(\sim 200 \mathrm{~nm}$ in thickness) and AlN $(\sim 150 \mathrm{~nm})$ layers on the Si substrate. Figure 1(b) shows a high-resolution TEM image of the $\mathrm{VO}_{2}$ and AlN layers with their electron diffraction patterns (EDPs), which indicate epitaxially well grown thin films of 


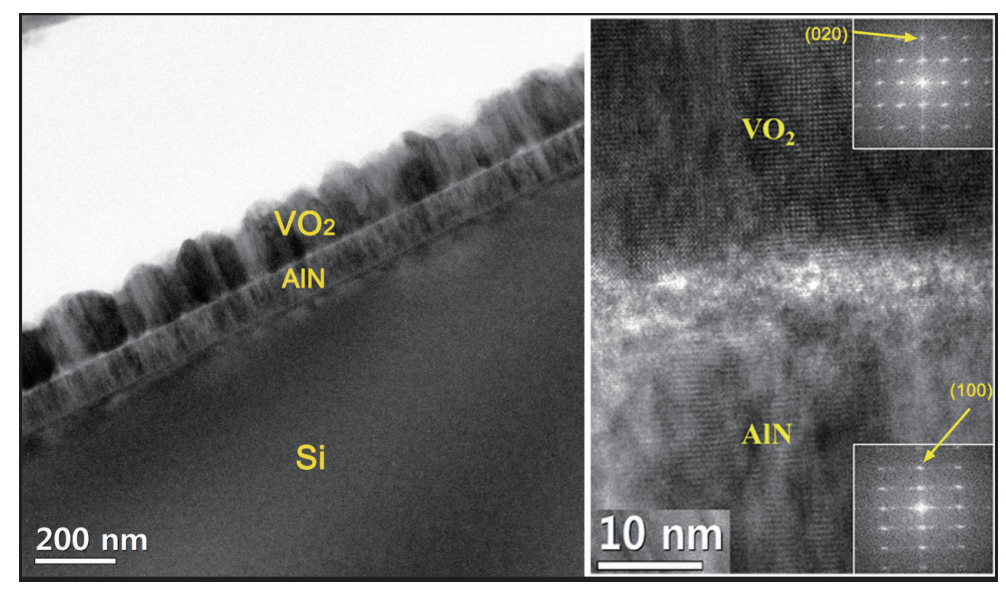

(a)

(b)

Fig. 1. (Color online) TEM images of $\mathrm{VO}_{2} / \mathrm{AIN} / \mathrm{Si}$ structure. (a) Bright and (b) high-resolution TEM images.

$\mathrm{VO}_{2}$ and $\mathrm{AlN}$. From the EDPs, AlN has a [100] direction normal to the Si substrate and $\mathrm{VO}_{2}$ has a [020] direction normal to the AlN layer.

$\mathrm{The} \mathrm{VO}_{2}$ thin film shows good properties with a resistance variation of $\sim 10^{4}$ times in the transition temperature region when it is grown on a sapphire board $\left(\mathrm{C}\right.$-plane $\left.\mathrm{Al}_{2} \mathrm{O}_{3}\right)$. However, since the price and process cost of sapphire substrates are relatively high, research on $\mathrm{VO}_{2}$ growth on other substrates is very important from the perspective of commercialization

\subsection{Package element manufacture}

The $\mathrm{VO}_{2}$ thin film was etched using a reactive-ion etching (RIE) system, and a $\mathrm{VO}_{2}$ channel with a device resistance of $50 \mathrm{M} \Omega$ was formed. The chip was designed to be $380 \times 380 \mu \mathrm{m}^{2}$, and $\mathrm{Ti}$ and $\mathrm{Au}$ electrodes of 30 and $300 \mathrm{~nm}$ thicknesses were formed, respectively. After cutting a cross section of $150 \mu \mathrm{m}$ thickness, each chip was cut crosswise.

Figure 2 shows an optical microscopy image of the structure fabricated by an elemental manufacturing process. The final package element was completed with two products packaged using two types of commercial LED package: SMD1608 and 3Ф lamp package. Clear epoxy was used as the molding compound.

Figure 3 shows the SMD1608 package with dimensions of $1.6 \times 0.8 \mathrm{~mm}^{2}$. This package is fabricated by the epoxy bonding of the chip to the printed circuit board (PCB) and widely used for displays and panels of small appliances.

Figure 4 shows a product that is packaged using $3 \Phi$ lamp specifications. The top of the package is flat, and only the upper part of the chip in the lead frame is molded into epoxy. This type of package is widely used for displays and sensors. The resistance of the final product, which was designed to be $50 \mathrm{M} \Omega$, was measured and the required jigs were manufactured and tested for their reliability. 


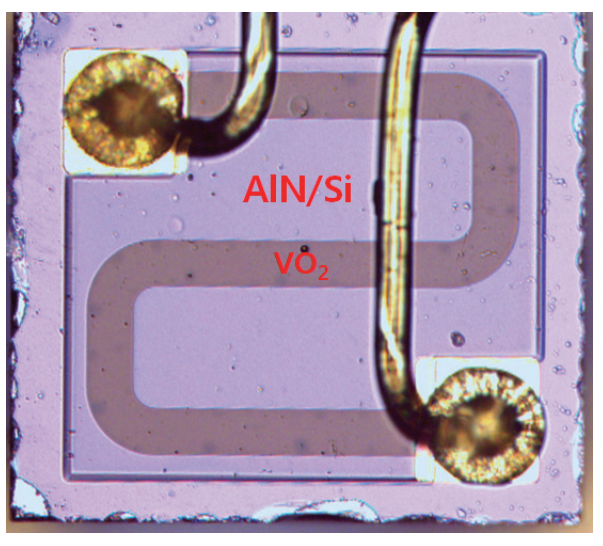

Fig. 2. (Color online) Image of temperature sensor chip.

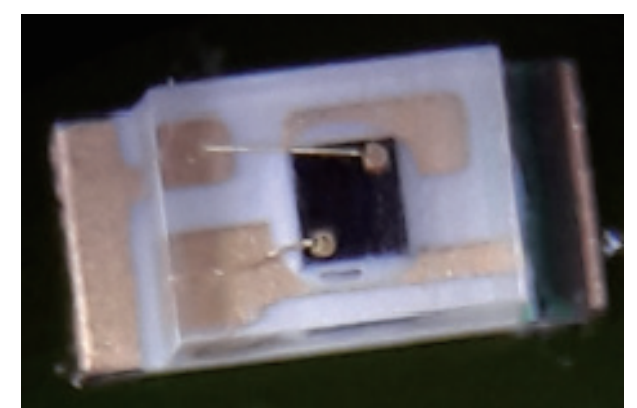

Fig. 3. (Color online) SMD1608 package structure.

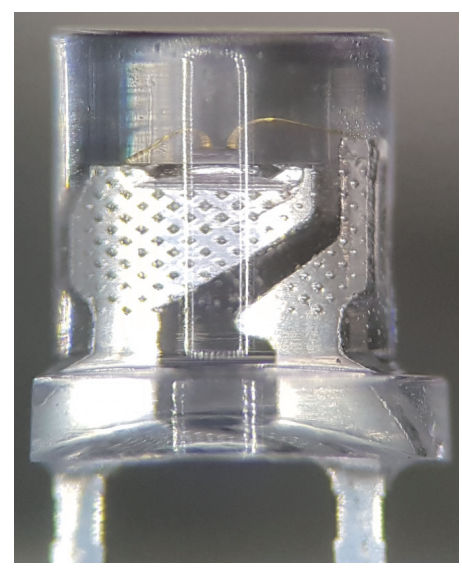

Fig. 4. (Color online) 3Ф Lamp package.

\section{Experimental Methods and Results}

\subsection{Analysis of basic characteristics}

$\mathrm{VO}_{2}$ has a rutile structure $(\mathrm{P} 42 / \mathrm{mnm})$ at its transition temperature and above $\left(T>T_{C}\right)$, but below its transition temperature $\left(T<T_{C}\right)$, it has a monoclinic structure $(\mathrm{P} 21 / \mathrm{c}) . \quad \mathrm{VO}_{2}$ shows a sharp decrease in resistance of $\sim 10^{4}$ order at around $T_{C}$ as the temperature increases. The reason is that $\mathrm{VO}_{2}$ changes from being a semiconductor to a metal with changes in crystal structure near temperatures at which resistance varies rapidly. In addition, $\mathrm{VO}_{2}$ is affected by the microstructure of the thin film, the transition temperature due to lattice strain, the hysteresis width, and the resistivity difference from electrical and optical perspectives. ${ }^{(8-11)}$ The $T_{C}$ of the element with the $\mathrm{VO}_{2} / \mathrm{AIN} / \mathrm{Si}$ structure was about $80{ }^{\circ} \mathrm{C}$. The reason why the transition temperature of $\mathrm{AIN} / \mathrm{Si}$ is higher than that of $\mathrm{VO}_{2}$ by about $13{ }^{\circ} \mathrm{C}$ seems to be the increase in phase transition temperature induced by the lattice strain during growth. 
Figure 5 shows the result of an XRD $\theta-2 \theta$ scan of a $\mathrm{VO}_{2}$ thin film grown by RF magnetron sputtering deposition on a $\mathrm{Si}(100)$ substrate. It was confirmed that the thin film grew at $500{ }^{\circ} \mathrm{C}$ epitaxially in the direction of the monoclinic $\mathrm{VO}_{2}\left(\mathrm{M}-\mathrm{VO}_{2}\right)(020)$. In addition, the half-width of the peak $\left(0.09^{\circ}\right)$ in the direction of $\mathrm{VO}_{2}(020)$ was found to be the same at all deposition temperatures. For the $\mathrm{VO}_{2}(020)$ direction peak, the strain between the $\mathrm{VO}_{2}$ film and the substrate was calculated as

$$
\text { strain }=\frac{d_{\text {film }}-d_{\text {bulk }}}{d_{\text {bulk }}} \times 100(\%),
$$

where $d_{f i l m}$ is the interplane distance of the film obtained from the Bragg law $(2 d \sin \theta=n \lambda)$ and $d_{\text {bulk }}(=2.2585 \AA)$ is the interplane distance of the bulk $\mathrm{VO}_{2} \cdot{ }^{(12,13)}$ It was found that $0.18 \%$ of strain was detected and that the entire film was subjected to tensile strain in the out-of-plane direction.

Figure 6 shows the result of an XRD $\omega$-rocking scan for $\mathrm{VO}_{2}(020)$ directional peaks. The half-width is $0.09^{\circ}$, which indicates that the mosaic crystals are good.

\subsection{Temperature resistance characteristics}

To investigate the changes in the resistivity and MIT characteristics of the $\mathrm{VO}_{2}$ thin film, the resistance was measured by raising and lowering the temperature. When the nonresistance, surface resistance, and thin film thickness are $\rho, \rho_{s}$, and $t$, respectively, the nonresistance in the thin film is calculated as. ${ }^{(14)}$

$$
\rho=\rho_{s} t=\left(\frac{V}{I}\right) \times C\left(\left(\frac{a}{d}\right):\left(\frac{d}{s}\right)\right) \times t .
$$

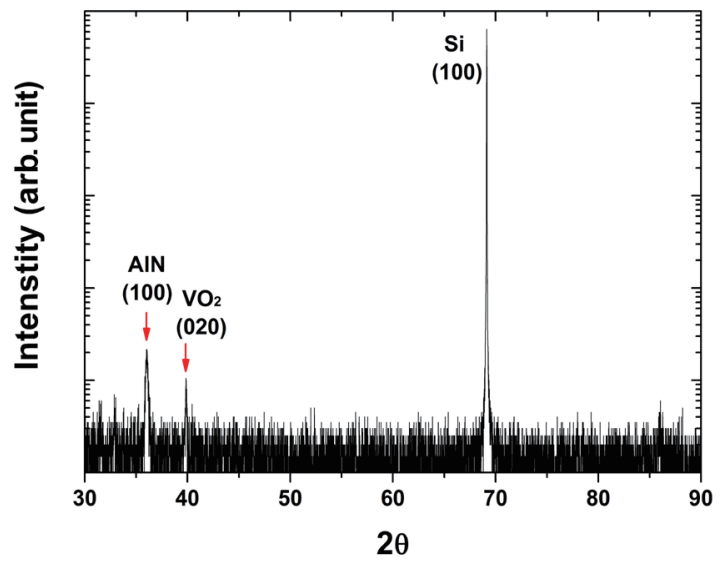

Fig. 5. (Color online) XRD analysis of vanadium oxide thin films.

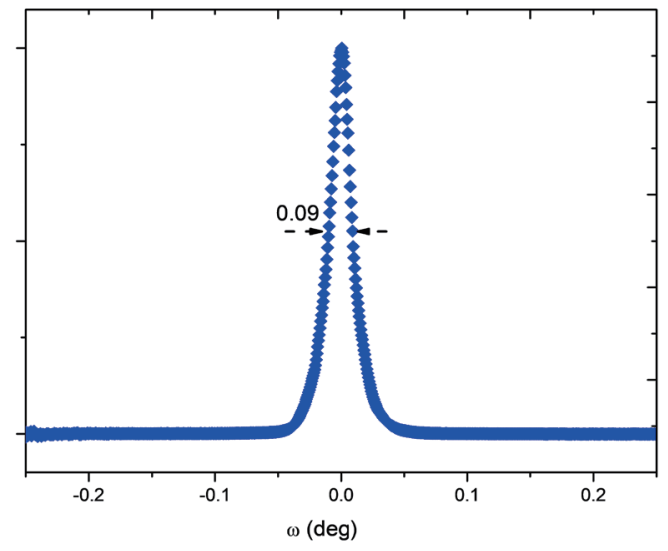

Fig. 6. (Color online) $\omega$-Rocking curves of vanadium oxide thin films. 
When a specimen is rectangular, $a, d$, and $s$ are the horizontal length of the specimen, the longitudinal length of the specimen, and the distance between the four terminals and the two terminals, respectively. $C$ is a constant value as a function of geometry. The experimental equipment used in the study (2000 DC and AC current source M3500 nanovoltmeter from Keithley Co.) was operated at $1 \mathrm{~mA}$, and voltage was measured to calculate resistance. In addition, resistance was measured by raising the temperature of the chamber for measuring the element from 1 to $100^{\circ} \mathrm{C}$.

Figure 7 shows the differential curve of nonresistance according to the temperature obtained from the equation $\mathrm{d}(\log \rho) / \mathrm{d} T$, which is the correlation between temperature and resistance as temperature rises. The $T_{C}$ of the MIT element is determined from the minimum of this differential curve. Figure 8 shows the differential curve of nonresistance according to temperature, which is the resistivity relationship from the zone of temperature when temperature is lowered. The resistance was $50 \mathrm{M} \Omega$ at room temperature and less than $5 \mathrm{k} \Omega$ above $80{ }^{\circ} \mathrm{C}$, which shows a resistance change of more than $10^{4}$ degrees at the transition temperature.

\subsection{Reliability experiment}

Reliability tests consist of an electrical characteristic test to evaluate the basic performance of a MIT temperature sensor, an environmental test to assess its environmental resistance, and a life test to determine its longevity.

The electrical characteristics were verified by the life and environmental tests. The life test was carried out under the conditions of high-temperature $\left(60^{\circ} \mathrm{C}\right)$ storage and low-temperature $\left(-25^{\circ} \mathrm{C}\right)$ storage. The environmental test was conducted at a high temperature $\left(85^{\circ} \mathrm{C}\right)$ and a high humidity $(85 \% \mathrm{RH})$. Ten temperature sensor samples per package type were used in the reliability tests conducted for $336 \mathrm{~h}$ each in the high-, low-, and constant-temperature/ constant-humidity chambers. The high-temperature/high-humidity tests determine whether the packaging material molded is sufficiently moisture-resistant. The polyamide series, a

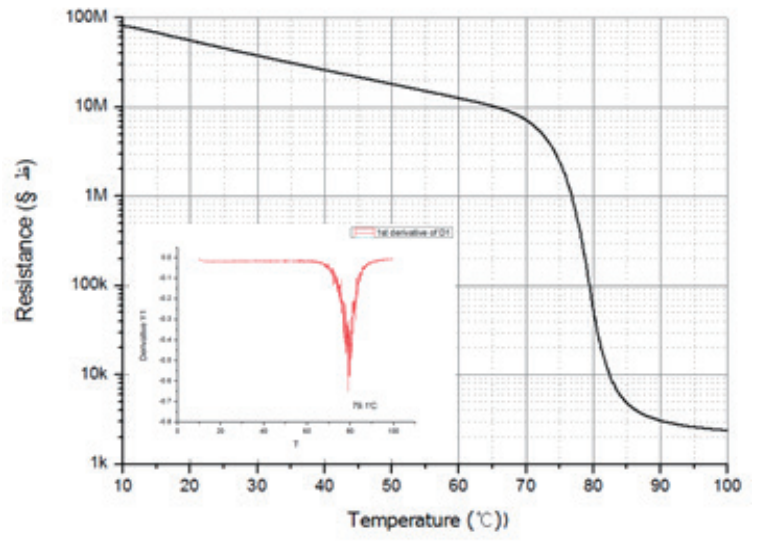

Fig. 7. (Color online) Temperature-dependent resistivity of $\mathrm{VO}_{2} / \mathrm{AIN} / \mathrm{Si}$ structure (temperature rise).

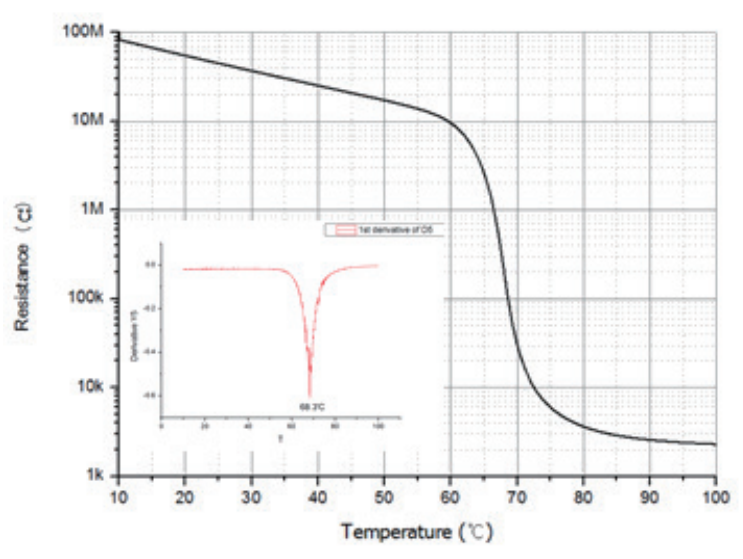

Fig. 8. (Color online) Temperature-dependent resistivity of $\mathrm{VO}_{2} / \mathrm{AIN} / \mathrm{Si}$ structure (temperature drop). 
clear compound, is vulnerable to humidity compared with conventional epoxy semiconductor molding packaging materials. It has no filler, has a relatively low expansion rate for heat, and is mainly used extensively as a packaging material for optical parts. In addition, to identify the weak points against humidity, reliability tests were carried out using the Si series epoxy material for each package type.

The temperature resistance characteristics of each sample were measured prior to the reliability tests. In general, the characteristics of MIT are such that the electrical resistance rapidly increases from $10^{2}$ to $10^{5} \Omega$ from a certain temperature to higher temperatures. $\mathrm{VO}_{2}$, which has a $T_{C}$ of $68{ }^{\circ} \mathrm{C}$, has a relatively high resistance at room temperature, making it difficult for the current to pass. However, when the temperature is gradually increased to above $T_{C}$, the resistance suddenly decreases and the current can easily pass.

Figure 9 shows the results of the high-temperature storage test of the temperature sensor. In the high-temperature $\left(60^{\circ} \mathrm{C}\right)$ storage test, the initial resistance of the devices packaged with SMD1608 and 3Ф lamp was about $52 \mathrm{M} \Omega$. After $336 \mathrm{~h}$, the resistance of the device packaged with SMD1608 increased to about $54 \mathrm{M} \Omega$, which was an increase of 5\%. The initial resistance of the device packaged with the $3 \Phi$ lamp product was about $53 \mathrm{M} \Omega$, and the resistance increased by about $6 \%$.

Figure 10 shows the results of the low-temperature $\left(-25{ }^{\circ} \mathrm{C}\right)$ storage test. The initial resistance of the devices packaged with SMD1608 and $3 \Phi$ lamp was about $51 \mathrm{M} \Omega$. After 336 $\mathrm{h}$, the resistance of the device packaged with SMD1608 increased to about $55 \mathrm{M} \Omega$, which was an increase of $7 \%$. The resistance of the device packaged with the $3 \Phi$ lamp increased to around $56 \mathrm{M} \Omega$ with a variation rate of $9 \%$.

The increase in resistance may be due to the shrinkage of the molding compound during the high-temperature storage, resulting in the increase in the resistance of the inner vanadium oxide element.

As shown in Fig. 11, the device packaged with SMD1608 exhibits a $20 \%$ increase in resistance to about $65 \mathrm{M} \Omega$ in the high-temperature/high-humidity test $\left(85^{\circ} \mathrm{C} / 85 \% \mathrm{RH}\right)$. The device packaged with the $3 \Phi$ lamp shows a $17 \%$ increase in resistance to $62 \mathrm{M} \Omega$. It was confirmed that the extent of increase was significantly greater in the high-temperature/high-

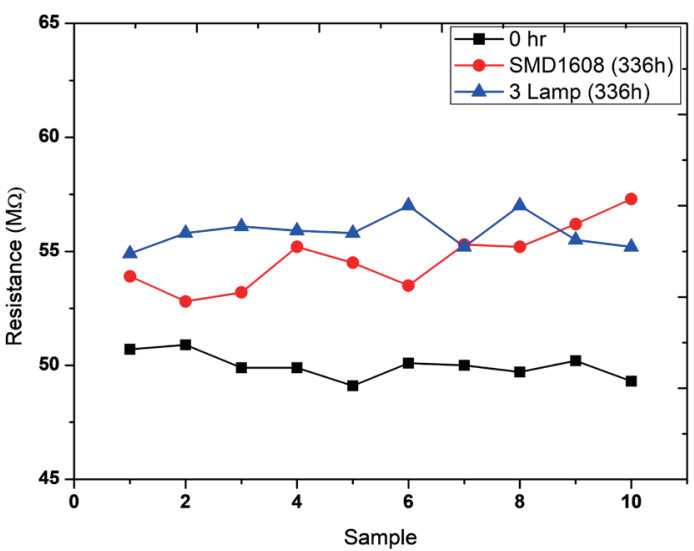

Fig. 9. (Color online) High-temperature storage test.

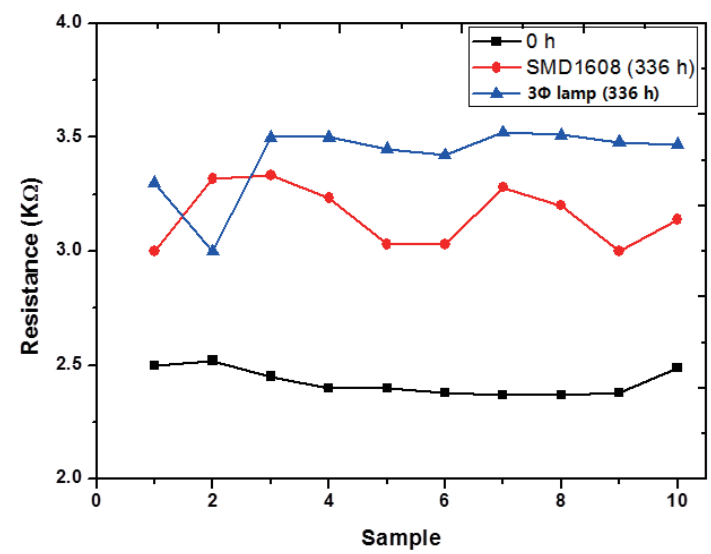

Fig. 10. (Color online) Low-temperature storage test. 


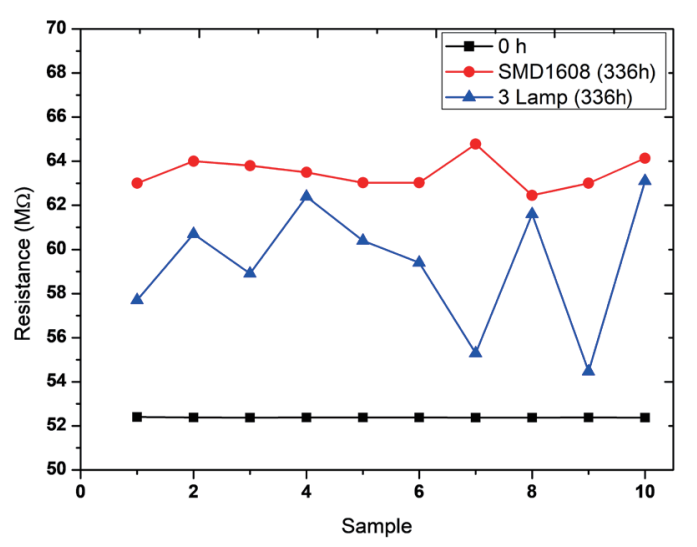

Fig. 11. (Color online) High-temperature/high-humidity test.

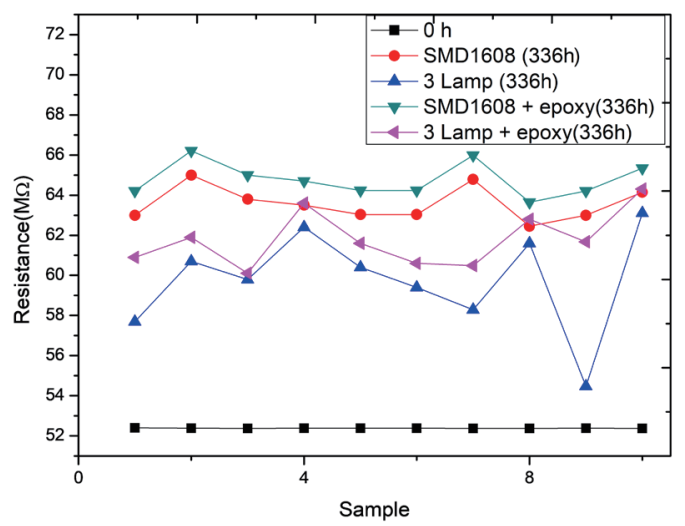

Fig. 12. (Color online) High-temperature/highhumidity test with epoxy.

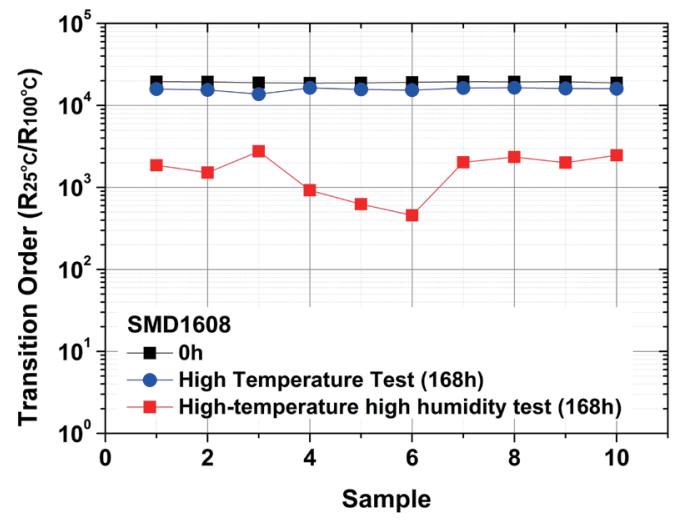

Fig. 13. (Color online) Transition order before and after life test.

humidity test than in the high-temperature and low-temperature storage tests. This is due to the delamination of the electrodes caused by the high humidity, moisture adsorption, and oxidation of lead wires. The delamination of the polymer electrode seems to have affected its reliability owing to the increase in resistance caused by the repeated adsorption and desorption of water depending on the external stress and environment conditions. Another reason is the effect of the expansion or contraction of the package itself on the thin film, and the moisture that penetrated into the package reacts with the oxygen on the surface of the vanadium oxide thin film, resulting in the chemical conversion of $\mathrm{VO}_{2}$ into $\mathrm{VO}_{x}$. At present, $\mathrm{V}_{2} \mathrm{O}_{5}$ has the largest resistance among $\mathrm{VO}_{x}$ compounds, so there is a possibility of using this compound instead of $\mathrm{VO}_{2}$.

Figure 12 shows that the device packaged with SMD1608 had a $22 \%$ increase in resistance to $66 \mathrm{M} \Omega$ in the high-temperature/high-humidity test $\left(85^{\circ} \mathrm{C} / 85 \% \mathrm{RH}\right)$, which was applied to each package prepared using silicon $(\mathrm{Si})$ series epoxy. The resistance of the device packaged with the $3 \Phi$ lamp device increased to about $63 \mathrm{M} \Omega$, which was an increase of about $17 \%$. Although epoxy was applied, it was found that it did not augment the effects of humidity on resistance.

Figure 13 shows the transition order, and the resistance ratios measured at 25 and $100{ }^{\circ} \mathrm{C}$ for the devices packaged with SMD1608. Usually, the transition order for good-quality $\mathrm{VO}_{2}$ 
is $\sim 10^{4}$. In the present study, the initial transition order denoted by a solid square at $0 \mathrm{~h}$ in Fig. 13 is $\sim 2 \times 10^{4}$, which means that the sample has good quality after packaging. After the hightemperature test for $168 \mathrm{~h}$, the transition order is $\sim 1.6 \times 10^{4}$, which showed a slight decrease. On the other hand, after the high-temperature/high-humidity test, the transition order markedly decreased to $\sim 2 \times 10^{3}$. This low humidity reliability means that moisture penetrated into the epoxy package and chemically reacted with the oxygen in $\mathrm{VO}_{2}$. However, more studies are required to clarify the precise mechanism underlying the decrease in the transition order of $\mathrm{VO}_{2}$ caused by high humidity. Finally, for $\mathrm{VO}_{2}$ devices to be commercially available, the development of packaging materials the prevent entry of air is required.

\section{Conclusion}

In this study, a temperature sensor was fabricated using $\mathrm{VO}_{2}$, and the deterministic properties of $\mathrm{VO}_{2}$ and the electrical characteristics of the device were confirmed. Also, the packages SMD1608 and 3Ф lamp were applied, and the reliability test was carried out. The results obtained were as follows. In the high-temperature $\left(60{ }^{\circ} \mathrm{C}\right)$ and low-temperature $\left(-25^{\circ} \mathrm{C}\right)$ storage tests, the resistance increased by $10 \%$ compared with initial resistance, but the resistance increased by $20 \%$ in the high-temperature/high-humidity test $\left(85^{\circ} \mathrm{C} / 85 \% \mathrm{RH}\right)$. This $20 \%$ increase was due to the greater effect of humidity and the larger increase in resistance in the high-temperature/high-humidity test than in the high-temperature and low-temperature storage tests. To compensate for this larger increase in resistance, in the high-temperature/highhumidity tests, silicon ( $\mathrm{Si}$ )-based epoxy was applied, but the increase was $22 \%$, which could not compensate for the increase in resistance caused by high humidity. Thus, it is necessary to study the internal lifting phenomenon and the oxidizing action in different types of package.

\section{Acknowledgments}

This study was supported by Wonkwang University in 2019.

\section{References}

R. L. Remke, R. M. Walser, and R. W. Bené: Thin Solid Films 97 (1982) 129.

2 W. Paul and M. Res: Mater. Res. Bull. 5 (1970) 691.

3 A. Ladd and W. Paul: Solid State Commun. 7 (1969) 425.

4 W. R. Roach: Appl. Phys. Lett. 19 (1971) 453.

5 M. Fukuma, S. Zembutsu, and S. Miyazawa: Appl. Opt. 22 (1983) 265.

6 J. M. Atkin, S. Berweger, E. K. Chavez, and M. B. Raschke: Phys. Rev. B 85 (2012) 020101.

7 M. Yang, Y. Yang, B. Hong, L. Wang, Z. Luo, X. Li, C. Kang, M. Li, H. Zong, and C. Gao: Ro. Soc. Chem. 5 (2015) 80122.

8 Z. Yang, C. Ko, and S. Ramanathan: Annu. Rev. 41 (2011) 337.

9 H. Ueda, T. Kanki, and H. Tanaka: Appl. Phys. Lett. 102 (2013) 153106.

10 P. Markov, K. Appavoo, R. F. Haglund, and S. M. Weiss: Opt. Express 23 (2015) 6878.

11 Z. Yang and S. Ramanathan: IEEE Photonics J. 7 (2015) 0700305.

12 B. Lazarovits, K. Kim, K. Haule, and G. Kotliar: Phys. Rev. B 81 (2012) 115117.

13 M. Yang, Y. Yang, B. Hong, L. Wang, Z. Luo, X. Li, C. Kang, M. Li, H. Zong, and C. Gao: Royal Soc. Chem. 5 (2015) 80122.

14 F. M. Smits: Bell Labs Tech. J. 37 (1958) 711. 


\section{About the Authors}

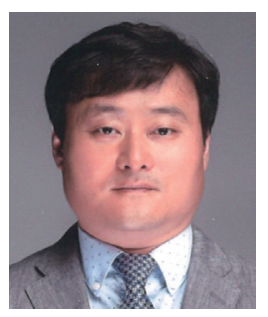

Beom-Su Kim received his bachelor's degree from the Business School of Wonkwang University in February 2015 and his master's degree from the Information and Communication Engineering Department of Wonkwang University in February 2017. From October 2009 to the present, he has been attending the Ph.D. program in the Information and Communication Engineering Department of Wonkwang University. He also serves as the CEO of Songbaek E\&S. His areas of interest are information management, information and communications, LED lighting and electrical and electronic materials.

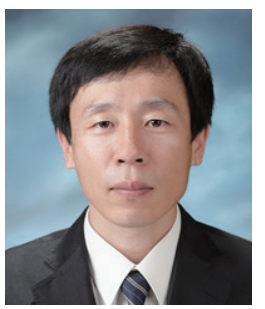

Bong-Jun Kim received his bachelor's degree in physics from Pusan National University in February 1994 and his doctorate degree in physics from Pusan National University in February 2003. He served as an ETRI researcher from October 2004 to August 2013. He served as the head of Mobile Research Center from October 2014 to April 2018. He currently serves as the CEO of Switching Plus. His areas of interest are information and communications, electrical/electronic and electronic materials.

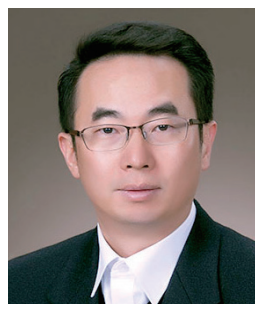

Sungkwan Youm received his B.S. degree in control instrumentation engineering from Hankuk University of Foreign Studies, Yongin, Korea in 1998, and his M.S. and Ph.D. degrees in electronics engineering from Korea University, Seoul, Korea in 2001 and 2006, respectively. From March 2006 to February 2015, he was with the Telecommunication Systems Division at Samsung Electronics Co., Ltd., Suwon, Korea. From March 2015 to February 2018, he was an assistant professor at the Department of Information and Communication, Cheju Halla University. Since March 2018, he has been an associate professor at the Department of Information and Communication Engineering, Wonkwang University. His current research interests include network security and computer network.

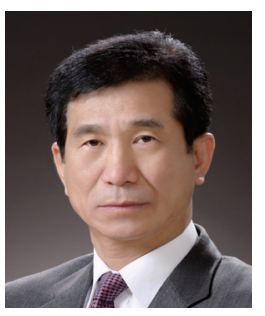

Dae-Hee Park graduated from Hanyang University in February 1979 with a bachelor's degree and served as a senior researcher at LS Cable \&amp and the Technology Research Institute from February 1979 to August 1991. In August 1983, he received his master's degree in electrical engineering from Hanyang University. In August 1989, he received his doctorate degree in electrical and electronic engineering from Osaka University. From September 1991 to the present, he has been a professor at the Information and Communication Engineering Department of Wonkwang University. His areas of interest are information and communications, electrical/electronics, electrical and electronic materials, and LED lighting. 